\title{
Improvement of Solar Cell Efficiency Using Nano-scale Top and Bottom Grating
}

\author{
Xiaomin Jin, Ashton Ellaboudy, and Greg Chavoor \\ Electrical Engineering Department, 1 Grand Avenue, \\ California Polytechnic State University, San Luis Obispo, CA, USA, 93407-9000
}

\begin{abstract}
We study solar-cell designs using nano-grating on both top (transmission) and bottom (reflection) of the solar cell. First, we perform simulations based on rigorous coupled wave analysis (RCWA) to evaluate the diffraction top gratins. In RCWA method, we calculate up to 20 harmonics, and sweep the launch angle of incident light from 0 to 90 degree. The incident light varies from $100 \mathrm{~nm}$ to $1200 \mathrm{~nm}$ wavelength. Triangular grating can achieve higher light absorption compared to the rectangular grating. The best top grating is around $200 \mathrm{~nm}$ grating period, $100 \mathrm{~nm}$ grating height, and $50 \%$ filling factor, which responses to $37 \%$ improvement for triangular grating and $23 \%$ for rectangular grating compared to non-grating case. Then, we use Finite-Difference Time-Domain (FDTD) to simulate transmission/reflection double grating cases. We simulated triangular-triangular (top-bottom) grating cases and triangular-rectangular (topbottom) grating case. We realize solar cell efficiency improvement about $42.4 \%$. For the triangulartriangular (top-bottom) grating case, the $20 \%$ efficiency improvement is achieved. Finally, we present weighted-light simulation for the double grating for the first time and show the best grating can achieve $104 \%$ light improvement, which is quite different from traditional non-weighted calculation.
\end{abstract}

Keywords: RCWA, FDTD, Solar cell, nano-grating

\section{INTRODUCTION}

It has been a long time, since the finding of photovoltaic effect by Bequerel in 1839. Recently, rapid industrial growth, urbanization, and increasing demands for consumer electronics, all of those lead to a very fast depletion of existing energy resource. Furthermore, in the past years, the awareness of the negative impacts of fossil fuel consumption on the environment has been increase. This leads to a very active alternative energy research. One of the solutions of above problem is the silicon solar cell. The solar cells or "photovoltaic device" can convert optical power from Sun to electricity. It is the best candidate for the next generation energy sources. They are low cost and easy to be fabricated [1] [2]. However, one of the major drawbacks is its fairly low absorption coefficient. Many approaches have been proposed to enhance the light trapping efficiency, such as adding back reflector [3] [4], designing periodic arrays of metal nanoparticles [5], modulating surface textures for enhancing light trapping [6], two-dimensional photonic crystal [7] [8], using light scattering textured back electrodes[10] [9][11], using diffraction grating [12][13], and photonic crystal back reflector [14], etc..

As the light transmission is affected by the shape and dimension of the grating, in this research we study the solar cell "photovoltaic device" light trapping under the variable nano-gratings. Gratings can vary in following ways: (1) by placing the grating on different layers within the solar cells, (2) by varying the density

Next Generation (Nano) Photonic and Cell Technologies for Solar Energy Conversion II, edited by Loucas Tsakalakos, Proc. of SPIE Vol. 8111, 811111 · @ 2011 SPIE · CCC code: 0277-786X/11/\$18 · doi: 10.1117/12.892807 
of grating cells on the grating layer, (3) by altering the shape of the grating cells, and (4) by increasing the symmetry of the photonic crystal grating. The top grating utilizes the scattering effects to allow more light coming into the solar cell to improve the overall trapping efficiency [5]. The silver back reflector grating is used in the thin-film silicon solar cells to reflect and scatter light, which was not absorbed during the first path through the solar cell [3]. The research presented in this paper simulates a variety of gratings, explores the transmission of light above the critical angle, studies the light reflection, and uncovers the mechanics behind light extraction from grating structures. This paper focuses on the transmission and reflection grating structure study and their design optimization. A single grating structure approximately doubles the light absorption and a double grating may also improve the total light trapping.

\section{SIMULATION MODEL}

We first propose to design a nano-scale photonic grating at the interface of solar cell to enhance the light transmission in order to improve the total absorption of the device, and perform a simulation of diffraction based on simplified two-dimensional (2D) rigorous coupled wave analysis (RCWA) to evaluate the concept of the diffraction grating application. RCWA is a rigorous grating diffraction theory which is used to study the mechanism of the diffraction of light from the periodic structured surfaces [15] [16] [17] [18]. RCWA represents the electromagnetic fields as a sum over coupled waves. Full vector Maxwell's equations are solved in Fourier domain to obtain each coupled wave, which is related to Fourier harmonic. Fourier harmonics are used for the periodic permittivity function in the calculation. Then the diffraction efficiencies are calculated. For each incident angle $\theta$, we calculate the transmitted -20 to +20 order diffraction efficiency. At the end of calculation, we obtained the transmittance by summing all the diffraction efficiencies. Compared to other methods, RCWA is a simple and quick method to design the top grating.

Secondly, we analyze a solar cell by the Finite Difference Time Domain (FDTD) method to simulation transmission/reflection double grating cases. Here the light source is placed on the top of solar cell. The time monitor is right in the center of cell to collect transmission power. Since FDTD is derived from Maxwell's equations, it can accurately simulate the small grating parameter effects of refraction in device materials, reflection due to linear dispersion or total internal reflection, transmission of light, and scattering at the grating. We begin with the differential forms of Maxwell's equations. From these equations, we break up these equations into the time-differentiated, spatial components of the curl operation of each respective axis in the Cartesian coordinate system,, which results in two sets of electric and magnetic components of the fields that will determine the characteristics of propagation of the light incident on the solar cell. Next, we employ a Yee's mesh, defined as interleaving E and H component fields [19][20]. Accuracy of a Yee's mesh is dependent on the grid size. The FDTD in conjunction with a Yee's mesh can simulate structures of arbitrary length and size. However, the model is limited in size due to the simulation time and amount of memory required to simulate larger devices. Methods to ease the requirements of three-dimensional models include use of Graphics Processing Units (GPU), parallel processing, and mode simplifications [21-23]. Since threedimensional model parameters scale in simulation time like N4 and in memory like N3, the two-dimensional FDTD is used in this paper to simulate this model to avoid unnecessary complications [24].

Shapes and sizing of the grate will determine the amount of the power generated by the cell based in the diffractions of the solar spectrum incident on the cell. The following types of gratings, triangular gratings and square gratings shown in Fig. 1 are one of the most studied structures based on their cost efficiency and simple yet efficient construction. One of the most popular methods of fabrication is called itching or laser scratching [3] [6]. To define a regular spacing between unit cells in a crystal lattice arrangement, we employ three parameters: grating cell period (A), grating cell height (d), and grating cell width (w). The grating cell period is the length from center-to-center between unit cells. In 3-D, the parameter w represents a diameter in the case of a circular structure (i.e. sphere, cone, and cylinder) or a length of a side in the case of a box structure 
(i.e. cube, rectangular cube). The grating cell height $d$ is the depth of the bottom hole. The simulated solar cells structure is shown in Fig.2. The two triangular lines represent the top and bottom grating respectively. The rectangular is the simulation window. The simulation wavelength can be set from $300 \mathrm{~nm}$ to $1100 \mathrm{~nm}$. The grating period sweep starts at $100 \mathrm{~nm}$ to $800 \mathrm{~nm}$ with $100 \mathrm{~nm}$ increment. We optimize the single top grating using rigorous coupled wave analysis (RCWA) method. Then we optimize the double grating (top-bottom) grating and compare the results with the non-grating case using FDTD. Finally, we sweep the input light wavelength and calculation weighted total light trapping efficiency according to Sun spectrum and silicon photo detector responsivity.

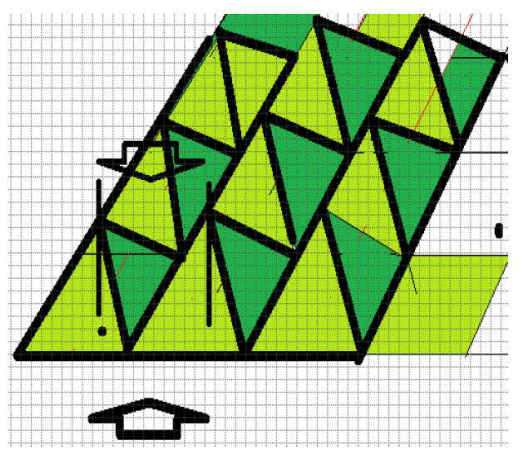

(a) Triangular grating

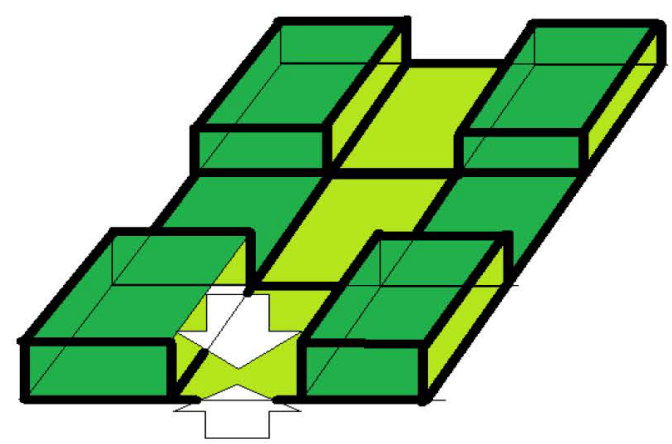

(b) Square grating

Figure 1. Grating structure studied in the paper

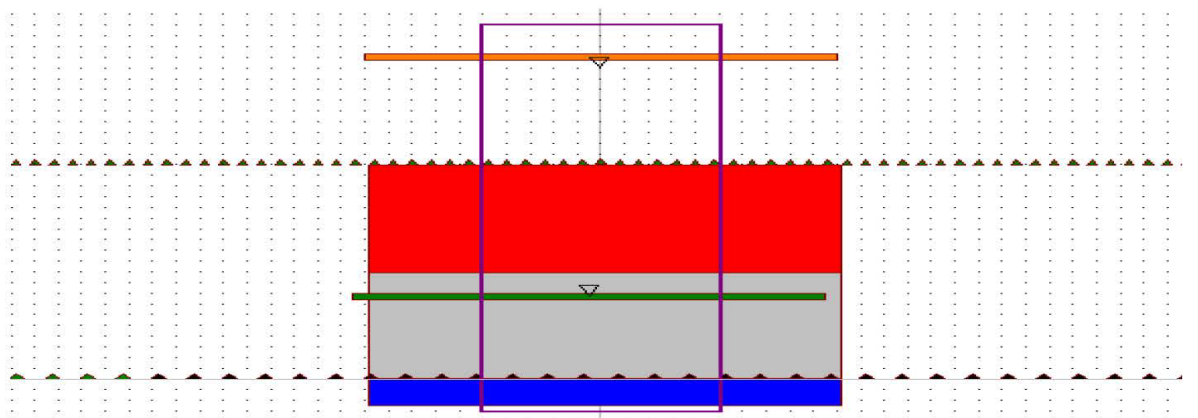

Figure 2. Two-dimension view of the solar cell

\section{SIMULATION RESULTS AND DISSCUSIONS}

We first use RCWA method to design the top grating structure, which is presented in Section 3.1. Then we study the top-bottom grating structure using FDTD since RCWA can only consider one transmission simulation and not reflection grating modeling.

\subsection{RCWA top grating design results}

The transmittance diffraction characteristics of the flat interface, rectangular photonic lattice grating, and triangular photonic lattice gratings are analyzed and compared. First, we assume that the gratings period 
$\mathrm{A}=200 \mathrm{~nm}$. While the bottom width of triangular grating is also $\mathrm{w}=200 \mathrm{~nm}$. In this case, the rectangular-profile is actually a square-profile. For simplicity in this simulation, we consider lossless dielectrics and incident electromagnetic plane wave polarization perpendicular to the plane of incidence. The results of the threeprofile comparison are shown in Fig. 3(a): the transmittance of flat surface (straight line), rectangular profile surface (long dashed line), and triangular profile surface (short dashed line) as function of incident light angle. The incident angle upon the normal of the grating from a plane wave is varied from 0 to $90^{\circ}$. This calculation is at $850 \mathrm{~nm}$ wavelength. The periodic gratings produce both forward diffracted (transmitted diffraction) and backward diffracted (reflected diffraction) waves. For a given incident angle $\theta$, the transmittance is the sum of the transmitted diffraction efficiency of all orders, which enters into Si through the gratings from the air. It is very clear that the triangular photonic lattice structure has the highest light transmittance. The square-profile photonic lattice is also better than the flat surface in general. The Fig. 3(b) presents the total light improvement (summation of transmission of the entire light incident angle) according to grating period variation. The triangular grating can achieves $36.6 \%$ light transmission improvement around grating period $A=200 \mathrm{~nm}$, which is better than that of rectangular grating, $22.08 \%$. Fig. 4 presents top grating design simulation at different wavelength with grating periods of (a) $200 \mathrm{~nm}$ and (b) $400 \mathrm{~nm}$. The figures show that the total transmission is oscillating versus the wavelength. And at some wavelength such as $500 \mathrm{~nm}$, the transmission rate of square-profile is better than that of the triangular grating. Our simulation shows clearly that a partial of blocked light can be extracted by using the transmitted diffraction of the nanoscale photonic-lattice.

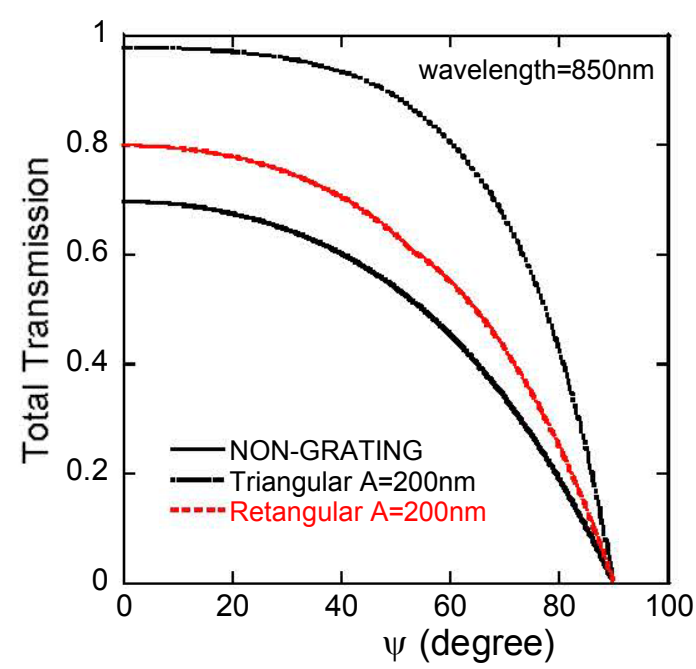

(a)

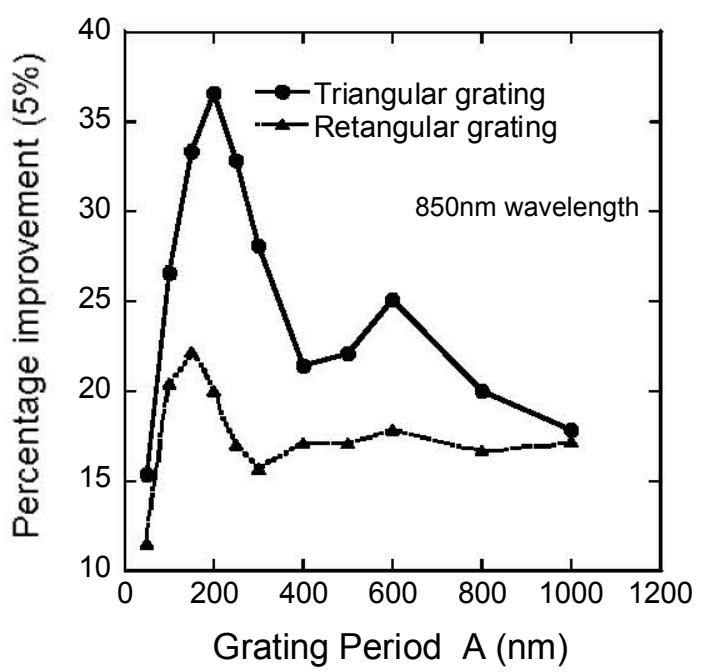

(b)

Figure 3. Top grating design simulation using RCWA (a) comparison of non-grating, triangular grating, and rectangular grating for grating period of $200 \mathrm{~nm}$, (b) total percentage improvement of light transmission according to difference grating period. 

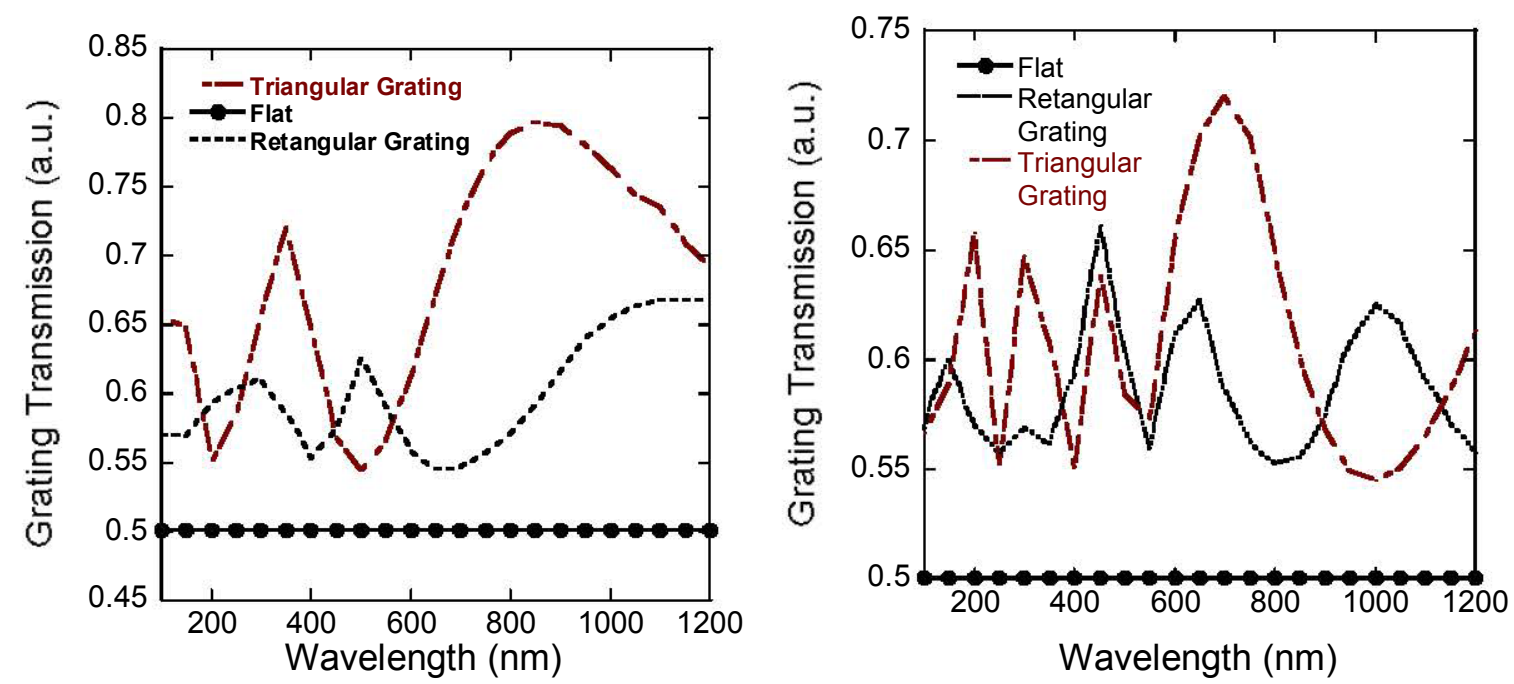

Figure 4. Top grating design simulation using RCWA: comparison of non-grating, triangular grating, and rectangular at different wavelength, grating periods are (a) $200 \mathrm{~nm}$ and (b) $400 \mathrm{~nm}$.

\subsection{FDTD top- bottom grating design}

First, we simulated double grating (top-bottom) light transmission at a single wavelength $850 \mathrm{~nm}$. From the RCWA simulation, the best top grating period is $200 \mathrm{~nm}$ triangular grating. Compared to non-grating solar cell of similar structure (the average power is about 0.5569 a.u.), we calculate the percentage improvement of light transmission for each case, which is listed in the Table 1 and Table 2.

Table 1: Simulation of triangular grating (top) and square grating (bottom)

\begin{tabular}{|c|c|c|c|c|}
\hline No. & $\begin{array}{c}\text { Top: triangular } \\
\text { grating }\end{array}$ & Bottom: square grating & $\begin{array}{c}\text { Power } \\
\text { (a.u.) }\end{array}$ & $\begin{array}{c}\text { Percentage } \\
\text { Improvement (\%) }\end{array}$ \\
\hline 1 & $100 \mathrm{~nm}$ & $100 \mathrm{~nm}$ & 0.58800 & 5.5845 \\
\hline 2 & $100 \mathrm{~nm}$ & $200 \mathrm{~nm}$ & 0.68400 & 22.823 \\
\hline 3 & $100 \mathrm{~nm}$ & $300 \mathrm{~nm}$ & 0.76200 & 36.829 \\
\hline 4 & $100 \mathrm{~nm}$ & $400 \mathrm{~nm}$ & 0.79300 & 42.395 \\
\hline 5 & $100 \mathrm{~nm}$ & $500 \mathrm{~nm}$ & 0.78900 & 41.677 \\
\hline 6 & $100 \mathrm{~nm}$ & $600 \mathrm{~nm}$ & 0.69415 & 24.645 \\
\hline 7 & $200 \mathrm{~nm}$ & $100 \mathrm{~nm}$ & 0.62602 & 12.412 \\
\hline 8 & $200 \mathrm{~nm}$ & $200 \mathrm{~nm}$ & 0.62762 & 12.699 \\
\hline 9 & $200 \mathrm{~nm}$ & $300 \mathrm{~nm}$ & 0.62319 & 11.903 \\
\hline 10 & $200 \mathrm{~nm}$ & $400 \mathrm{~nm}$ & 0.62425 & 12.094 \\
\hline 11 & $200 \mathrm{~nm}$ & $500 \mathrm{~nm}$ & 0.62524 & 12.272 \\
\hline 12 & $200 \mathrm{~nm}$ & $600 \mathrm{~nm}$ & 0.62265 & 11.806 \\
\hline
\end{tabular}


Table 2 : Simulation of triangular grating (top), triangular grating (bottom)

\begin{tabular}{|c|c|c|c|c|}
\hline No. & $\begin{array}{c}\text { Top: triangular } \\
\text { grating }\end{array}$ & Bottom: triangular grating & $\begin{array}{c}\text { Power } \\
\text { (a.u.) }\end{array}$ & $\begin{array}{c}\text { Percentage } \\
\text { Improvement (\%) }\end{array}$ \\
\hline 1 & $200 \mathrm{~nm}$ & $100 \mathrm{~nm}$ & .66 & 19.6 \\
\hline 2 & $200 \mathrm{~nm}$ & $200 \mathrm{~nm}$ & .67 & 20.3 \\
\hline 3 & $200 \mathrm{~nm}$ & $300 \mathrm{~nm}$ & .668 & 19.9 \\
\hline 4 & $200 \mathrm{~nm}$ & $400 \mathrm{~nm}$ & .644 & 15.6 \\
\hline 5 & $200 \mathrm{~nm}$ & $500 \mathrm{~nm}$ & .666 & 19.6 \\
\hline 6 & $200 \mathrm{~nm}$ & $600 \mathrm{~nm}$ & .628 & 12.7 \\
\hline
\end{tabular}

We simulate triangular-rectangular (top-bottom) grating cases (Table 1) and triangular-triangular (topbottom) grating case (Table 2) at $850 \mathrm{~nm}$ wavelength. By varying the bottom reflection grating period from $100 \mathrm{~nm}$ to $600 \mathrm{~nm}$ and keep the top grating fixed as $100 \mathrm{~nm}$-period triangular grating, we realize solar cell efficiency improvement about $42.4 \%$. For the triangular-rectangular (top-bottom) grating case, the $20 \%$ efficiency improvement is achieved. It is also shown that $100 \mathrm{~nm}$ top grating performs better compared to that of $200 \mathrm{~nm}$ top grating. And the triangular-triangular grating is better than triangular-square gratings. The detailed triangular-square gratings performances are shown in Fig. 5 according to different grating period and wavelength. However, it is hard to tell which the best grating from Fig. 5 is.

For solar cell study, it is very important to consider the Sun spectrum and Silicon photo detector responsivity into our simulation, which are highly wavelength dependent, shown in Fig. 6(a). The weighted factor for solar cell simulation can be obtained form the Sun spectrum and Silicon photo detector responsivity. We use the spectrum power on the solar system at the sea level. The chart represented the weighted values of the different wavelength design simulation. As we might be able to distinguish the highest power generated among all the cases, it is clear that the solar cells that have the $300 \mathrm{~nm}$ triangular grating at the top and square grating at bottom have the best weighted light trapping improvement as you can notice from the Figure 6 . At this specific design, the best light absorption efficiency improvement is about $104 \%$ compared to the nongrating case. This is the first simulation result in weighted total solar cell light trapping simulation without considering active region design. 


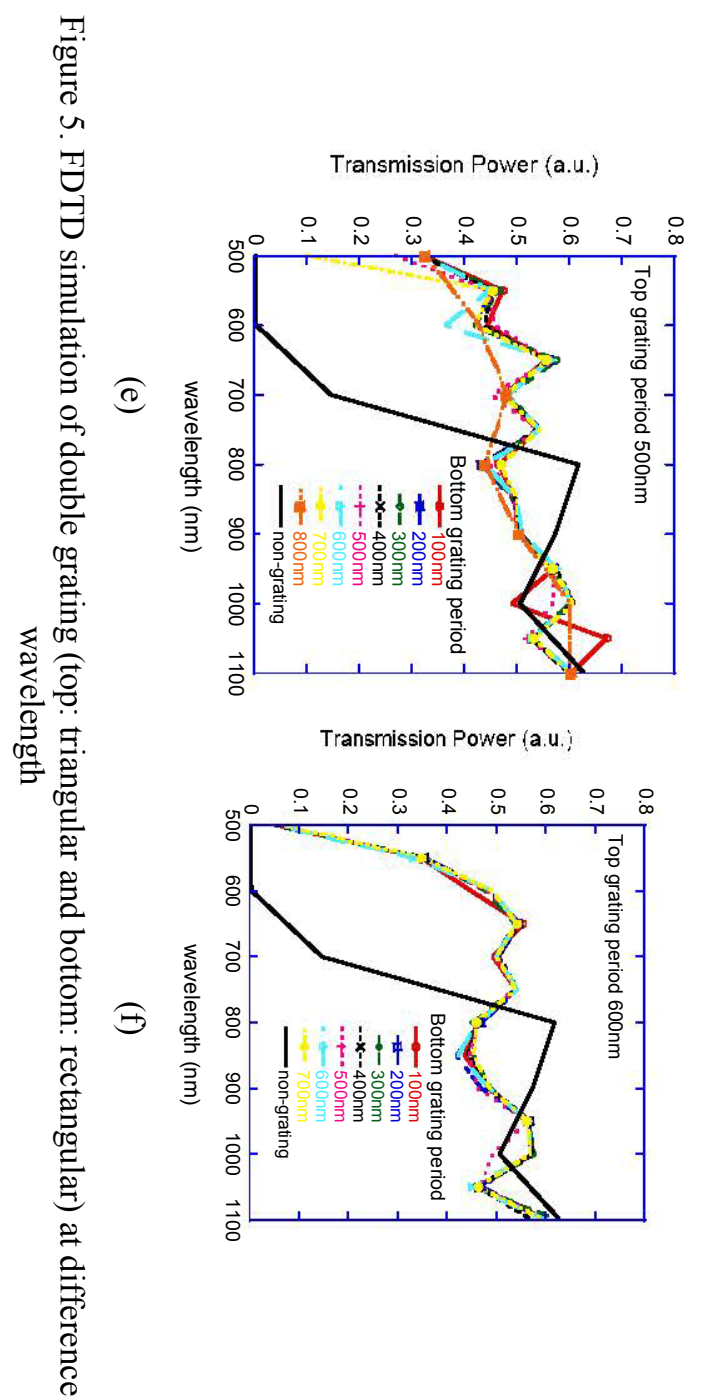

a

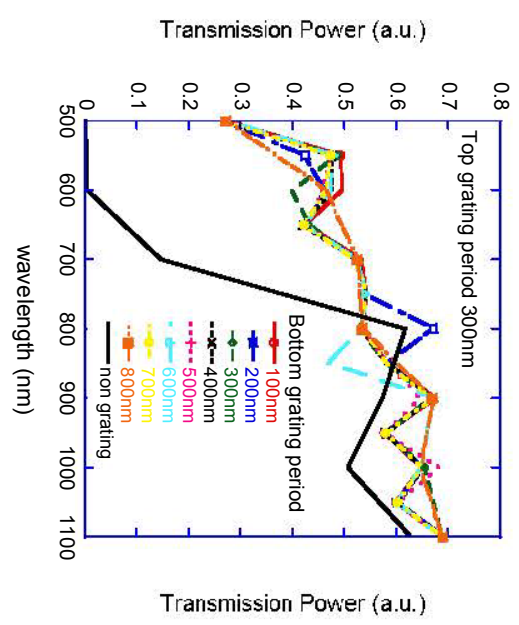

a

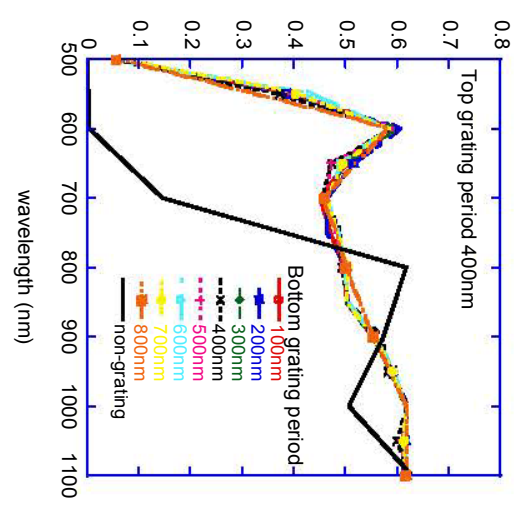

(2)

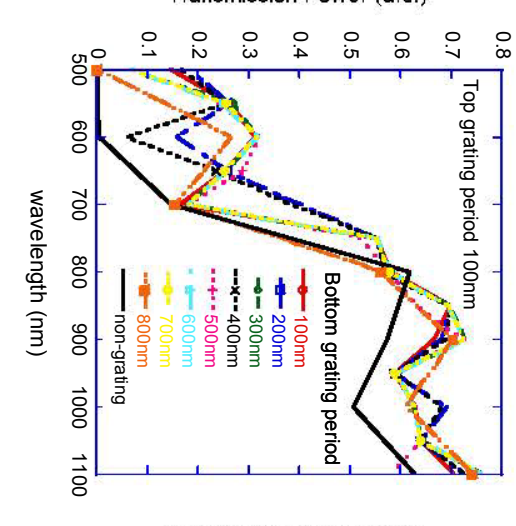

o

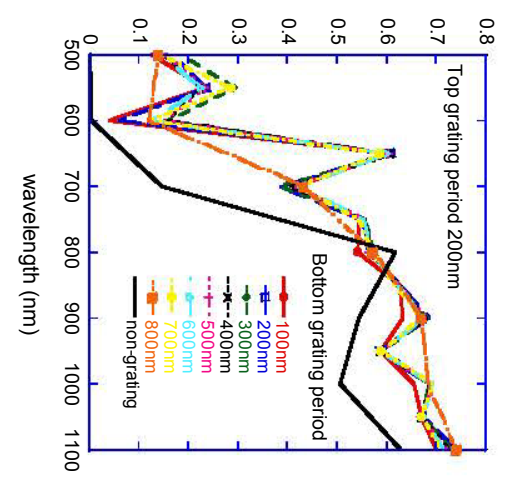




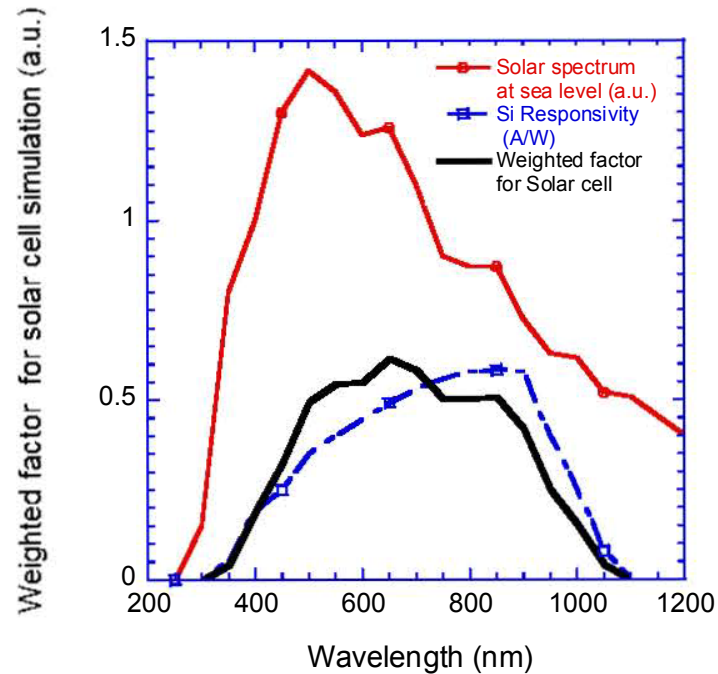

(a)

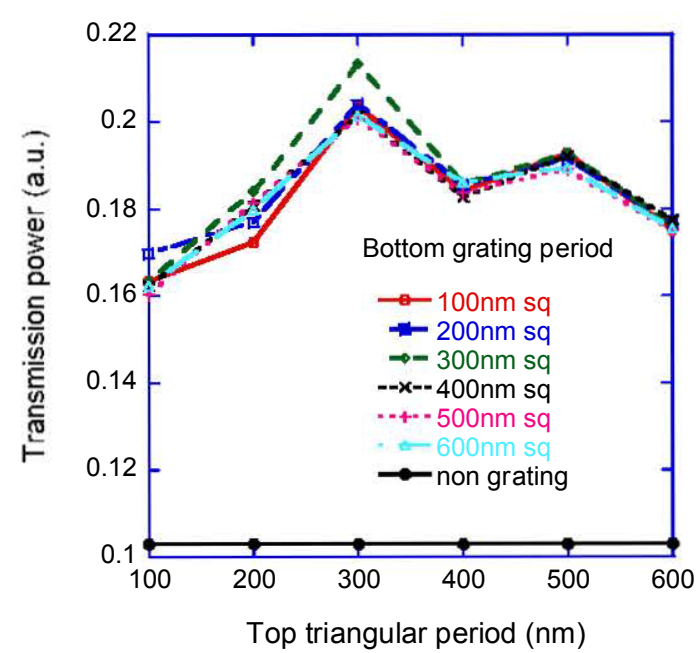

(b)

Figure 6. (a) Weighted factor for solar cell simulation and (b) The total weighted light absorption to the center of solar cells.

\section{CONCLUSION}

Based on this study we find that the combination of the triangular surface and a triangular surface will yield the optimal result taking in consideration the effect of the practical solar spectrum incident on the detector. We simulated triangular-triangular (top-bottom) grating cases and triangular-rectangular (top-bottom) grating case. By varying the bottom reflection grating period from $100 \mathrm{~nm}$ to $800 \mathrm{~nm}$ and keep the top grating fixed as $100 \mathrm{~nm}$-period triangular grating, we realize solar cell efficiency improvement about $42.4 \%$. For the triangular-rectangular (top-bottom) grating case, the $20 \%$ efficiency improvement is achieved. With consideration of Sun spectrum and Si responsivity, the best weighted light trapping efficiency improvement is about $104 \%$ compared to the non-grating case. This is the first simulation result in weighted total solar cell light trapping simulation without considering active region design.

\section{ACKNOWLEDGEMENT}

This project is supported by NSF Grant IRES Award \#1029135 and Chinese National Key Research Lab Collaboration Grant 2010, Peking University in China.

\section{REFERENCES}

[1] Feng, N.N., Michel, J., Zeng, L., Liu, J., Hong, H. Y., Kimerling, L.C., and Duan, X.., "Design of Highly Efficient Light-Trapping Structures for Thin-Film Crystalline Silicon Solar Cells," IEEE Trans. Electron Devices, 54(8), 1926-1933 (2007).

[2] Subash, S., and Chowdhury, M.H., "High efficiency carbon nanotube based solar cells for electronics devices," Proc. the 12th International Symposium on Integrated Circuits, 240 - 243(2009). 
[3] Springer, J., Poruba, A., Mullerova, L., Vanecek, M., Kluth, O., and Rech, B., “Absorption loss at nanorough silver back reflector of thin-film silicon solar cells,” J. App. Phys., 95(3), 1427 - 1429 (2004).

[4] Sai, H., Fujiwara, H., Kondo, M., and Kanamori, Y., "Enhancement of light trapping in thin-film hydrogenated microcrystalline Si solar cells using back reflectors with self-ordered dimple pattern," Appl. Phys. Lett., 93(14), 142501-142501-3 (2008).

[5] Mokkapati, S., Beck, F. J., Polman, A., and Catchpole, K. R., "Designing periodic arrays of metal nanoparticles for light-trapping applications in solar cells, Appl. Phys. Lett., 95(5), 053115-053115-3 (2009).

[6] Isabella, O., Krc, J., and Zeman, M., "Modulated surface textures for enhanced light trapping in thin-film silicon solar cells,” Appl. Phys. Lett., 97(10), 101106 (2010).

[7] Gomard, G., Drouard, E., Letartre, X., Meng, X.,; Kaminski, A., Fave, A., Lemiti, M., Garcia-Caurel, E., and Seassal, C., "Two-dimensional photonic crystal for absorption enhancement in hydrogenated amorphous silicon thin film solar cells," J. App. Phys., 108(12), 123102 - 123102-8 (2010).

[8] Zhou, D., and Biswas, R., "Photonic crystal enhanced light-trapping in thin film solar cells," J. App. Phys., 103(9), 093102 - 093102-5 (2008).

[9] Paulick, T. C., "Textured back surface reflectors for thin film solar cells," J. App. Phys., 62(7), 3016 3024 (1987).

[10] Franken, R. H., Stolk, R. L., Li, H., Van der Werf, C. H. M., Rath, J. K., and Schropp, R. E. I., "Understanding light trapping by light scattering textured back electrodes in thin film n-i-p-type silicon solar cells," J. App. Phys., 102(1), 014503 - 014503-7 (2007).

[11] Haase, C. and Stiebig, H., "Thin-film silicon solar cells with efficient periodic light trapping texture," Appl. Phys. Lett., 91(6), 061116 - 061116-3 (2007).

[12] Dewan, R. and Knipp, D., "Light trapping in thin-film silicon solar cells with integrated diffraction grating," J. of App. Phys., 106(7), 074901 - 074901-7 (2009).

[13] Tobias, I., Luque, A., and Marti, A., "Light intensity enhancement by diffracting structures in solar cells," J. App. Phys., 104(3), 034502 - 034502-9 (2008).

[14] Zeng, L., Yi, Y., Hong, C., Liu, J., Feng, N., Duan, X., Kimerling, L. C., and Alamariu, B. A., "Efficiency enhancement in Si solar cells by textured photonic crystal back reflector," App. Phys. Lett., 89 (11), 11111-11111-3 (2006).

[15] Moharam, M. G., and Gaylord, T. K. "Rigorous coupled-wave analysis of metallic surface-relief gratings," J. Opt. Soc. Am. A 3, 1780 (1986).

[16] Li, L., "New formulation of the Fourier modal method for crossed surface-relief gratings," J. Opt. Soc. Am. A 14, 2758 (1997).

[17] Jiang, M., Tamir, T., and Zhang, S., "Modal theory of diffraction by multilayered gratings containing dielectric and metallic components," J. Opt. Soc. Am. A 18, 807 (2001).

[18] Abouelsaood, A. A., Ghannam, M. Y., and Al Omar, A. S., "Limitations of ray tracing techniques in optical modeling of silicon solar cells and photodiodes," J. App. Phys., 84(10), 5795-5801 (1998).

[19] Yee, K., "Numerical solution of initial boundary value problems involving Maxwell's equations in isotropic media," IEEE Trans. Antennas and Propagation, 14, 302-307 (1966).

[20] Campa, A., Krc, J., and Topic, M., "Analysis and optimisation of microcrystalline silicon solar cells with periodic sinusoidal textured interfaces by two-dimensional optical simulations," J. App. Phys., 105(8), 083107 - 083107-5 (2009).

[21] Adams, S., Payne, J., and Boppana, R., "Finite Difference Time Domain (FDTD) Simulations Using Graphics Processors,” HPCMP Users Group Conference, (2007).

[22] Liu, Z. M., Mohan, A. S., Aubrey, T. A., and Belcher, W. R., "Techniques for Implementation of the FDTD Method on a CM-5 Parallel Computer,” IEEE Ant. And Prop. Mag., 37, 64-71 (1995).

[23] Chen, Y., Simpson, T. L., Ho, T. Q., "Highly efficient technique for solving radiation and scattering problems," IEEE Proc., 139, 7-10 (1992).

[24] Catchpole, K. R. and Green, M. A., "A conceptual model of light coupling by pillar diffraction gratings," J. App. Phys., 101(6), 063105 - 063105-8 (2007). 